\title{
A New Fault-Ride-Through Strategy for MTDC networks incorporating Wind Farms and Modular Multi-Level Converters
}

\author{
D. Tzelepis ${ }^{\mathrm{a}^{*}}$, A. Oulis Rousis ${ }^{\mathrm{b}}$, A. Dyśko ${ }^{\mathrm{a}}$, C. Booth ${ }^{\mathrm{a}}$, G. Strbac ${ }^{\mathrm{b}}$ \\ ${ }^{a}$ Department of Electrical and Electronic Engineering, University of Strathclyde, Glasgow, UK \\ ${ }^{b}$ Department of Electrical and Electronic Engineering, Imperial College, London, UK \\ *Technology \& Innovation Centre, 99 George Street, G11RD, Glasgow, UK \\ e-mail: dimitrios.tzelepis@strath.ac.uk \\ tel: $+44(0) 1414447268$
}

\begin{abstract}
This paper presents a DC voltage control strategy for enhancing the fault-ride-through (FRT) capability of wind farms comprising of fully rated converter permanent magnet synchronous generators (FRC-PMSGs) connected to multi-terminal high voltage direct current (MT-HVDC) grids through modular multi-level converters (MMCs). The proposed FRT strategy is implemented on a master controller located in the offshore AC substation of each wind farm. The underlying issue addressed via the scheme relates to overvoltages in the HVDC links when the power transfer is disrupted due to faults occurring in the AC onshore grid. The corresponding Matlab/Simulink ${ }^{\circledR}$ model has been validated using transient simulation, while the practical feasibility of the controller is demonstrated utilising Opal-RT ${ }^{\mathfrak{C}}$ real-time hardware platform.

Keywords: Fault-Ride-Through, Multi-Terminal High Voltage Direct Current, Modular Multilevel Converters, DC Voltage Control, Permanent Magnet Synchronous Generators.
\end{abstract}

\section{Introduction}

In recent years, the development and commissioning of wind farms (WFs) has risen significantly in an attempt to satisfy the increasing need for electricity demand, whilst meeting the targets for decarbonising the power sector $[1,2]$. Large-scale offshore WFs have especially attracted vast attention due to higher average wind speeds and less visual impact observed in remote locations $[3,4,5]$. The AC transmission system solutions commonly deployed in such WFs pose challenges such as efficiency levels, power transfer capability and requirement for reactive power compensation [6]. With the advancement of HVDC technologies in the last decade, a few offshore WFs have been built, and many more are planned, to take advantage of the DC systems benefits and largely overcome the shortcomings of the AC counterparts [7,8].

Apart from the technical issues, stringent regulatory requirements for connecting WFs to the main grid have also been introduced [9]. Specifically, the regulations have been reviewed to make sure that the pro- 
liferation and safe integration of distributed generation are in line with the rigorous measures designed to ensure uninterruptible power flow and high quality of supply [10]. The driving force behind these challenges is the fault-ride-through (FRT) requirement imposed by grid codes, which implies that WFs should remain connected during and following certain disturbances minimising the unsupplied demand [11]. The associated risks of this initiative, however, may be serious and include power balance disruption, and hence a dangerous increase of the DC link voltage as a result of the fault occurrence onshore [12]. Significant over-voltages could potentially impact the lifetime of the cable (e.g. for single-phase faults) or even cause its permanent damage (e.g. in extreme cases of major three-phase faults) [13].

Several methods have been used for maintaining the DC voltage within acceptable limits during faults, but with additional FRT compliant protection circuitries [14]. Such systems impose higher capital costs, waste of energy, or the need for communication between the HVDC converter stations and the WF [15]. Therefore they are considered slow for a given short duration of the faults. More advanced schemes propose that after identifying the DC over-voltage, an over-frequency condition on the offshore AC grid or an emulated short-circuit at the offshore HVDC converter station can be imposed to force the individual wind turbine controllers decrease their active power output with no need for additional equipment or communication links [16]. These methods are not favoured, as they need to interpret the fault into a certain state at the offshore AC grid before action is initiated.

This paper proposes an innovative communication-less FRT strategy, which can provide a fast enough response to effectively mitigate the detrimental fault effects. Furthermore, unlike the approaches in [15, 14], no extra hardware (i.e. DC link chopper) is required, and there is no unnecessary power dissipation. The proposed methodology is applied to a state-of-the-art meshed network, consisting of a three-terminal HVDC system equipped with MMC-HVDC converters, in order to fully demonstrate its benefits.

\section{FRT control strategies}

Under healthy operating conditions, grid-connected offshore WFs operate at their maximum export capacity (e.g. with MPPT) and the offshore HVDC converter station injects the available electrical power into the DC links, and further to the mainland AC transmission system via the onshore HVDC converter. However, when faults occur in the AC system in close proximity to the onshore HVDC converter station (or there are voltage dips as a result of other remote $\mathrm{AC}$ faults), the latter cannot effectively transfer the produced power into the main grid. Since the connected WFs continue to produce uninterruptibly power that cannot be entirely delivered during the voltage sags, this leads to power imbalance between the onshore and 
offshore HVDC converter stations potentially causing over-voltages in the DC link. These over-voltages, if not mitigated, can endanger the integrity of the power electronic devices and other associated HVDC equipment. As disconnection of the WFs is not allowed due to the FRT requirements stipulated by grid codes, these over-voltages should be rapidly constrained to an acceptable level.

\subsection{Review of Existing Methods}

Many software and/or hardware solutions that can facilitate FRT compliance, whilst also limiting the resulting over-voltages, have been reported in the open literature. These can be classified into the following three major categories:

- Fast reduction of WF active power output: This method relies on de-loading of the WF active power output either from the generator controller or the grid-side controller, which suppresses the rise of DC voltage [16]. Based on this principle, many different approaches have been proposed $[15,17,14,18,19]$, all aiming at avoiding the use of additional equipment, and therefore lowering the cost and power losses. It is noted, though, that there are numerous challenges yet to be considered including properly handling mechanical stresses, overcoming the need for communication signals to achieve faster responses, and addressing the frequency/angular stability issues of the AC system.

- Emulation of over-frequency or short-circuit on the offshore AC side of the system: This is a deloading control strategy in which the offshore HVDC controller is used to impose a certain operating condition into the offshore $\mathrm{AC}$ side in reflection to an interpretation of the onshore $\mathrm{AC}$ side fault. Regarding the over-frequency disturbance [20,15,14], by moving an over-frequency event close to the offshore HVDC converter, the wind turbines active power output can be accordingly reduced via fast frequency control that increases the AC grid frequency in proportion to the DC voltage rise. This method introduces many challenges especially in FRC wind turbines where the mechanical slip is decoupled and fast frequency control is required. Additional challenges may arise regarding the frequency measurement during disturbances and the tuning of the corresponding controllers. As far as the emulated short-circuit strategy is concerned $[18,21,16]$, the rapid increase of the DC link voltage is monitored and the amplitude modulation index is appropriately reduced, which results in a decrease of the HVDC converter station voltage, consequently allowing the WFs to detect the fault on the offshore side. Nevertheless, in such case high transient currents are expected to be generated at the beginning and end of the fault, which could potentially harm the semiconductor devices of the 
offshore HVDC converters. Note that both concepts require application of additional control schemes in the offshore HVDC converter station.

- Use of additional equipment to dissipate energy: This approach utilises a fully-rated DC chopper connected in series with a regeneration resistor in the HVDC link, which is also referred to as the dynamic braking system $[14,16,22]$. The energy excess is dissipated through the resistor to keep the DC voltage within acceptable limits. The method is advantageous as the WF remains in operation, and is also suitable when HVDC systems are connected to weak AC networks. The downside aspects are added cost, increased substation footprint, and more importantly significant waste of produced energy until the fault is cleared.

\subsection{Proposed Method}

A DC voltage control strategy put forward in this paper is implemented by a master controller (per individual wind farm) located in the offshore AC network area. Such controller determines the active power reference in relation to the DC voltage measurement received from the HVDC transmission system (e.g. DC voltage $V_{d c}$ amplitude and its rate of change i.e. $d v_{d c} / d t$ ). The DC voltage measurement can be received by existing bus-level communication links between wind farms and their substations. From this point of view and due to the fact that long communication links are not required between VSC stations and/or AC offshore and onshore platforms, the proposed scheme can be characterised as communicationless. The control principle is essentially based on the fact that a fault on the AC side of the onshore grid disrupts the transfer of power onshore and therefore induces a certain amount of over-voltage in the DC link of the transmission system. Examples of such transients include faults at the AC connection point, but also voltage dips coming from other remote AC faults. The controller then outputs a power reference $\left(P_{W F}^{*}\right)$, which is further used to generate the corresponding MPPT torque reference $\left(T_{\text {set }}\right)$ for the MSC controller as shown in Fig. 3(a). In steady state, the offshore WF operates at the power reference denoted by $P_{W F(a)}^{*}$ in Fig. 1. This is mainly determined by the MSC torque controller as it will be explained in Section 3.2, but during this stage the DC voltage status of the HVDC link has no effect on the master controller.

Upon a fault inception on the AC side of the onshore grid, over-voltages in the DC link of the transmission system are foreseen because of the resulting power imbalance between the two HVDC converters as discussed earlier. During such a transient, an over-voltage element (set to 1.02 p.u. of the rated DC voltage) will force the power reference to take $d v_{d c} / d t$ dependent values denoted by $P_{W F(b)}^{*}$ on the power curve shown in Fig. 1. The time window of the differentiators $d / d t$ has been set to $4 \mathrm{~ms}$. Two critical values 


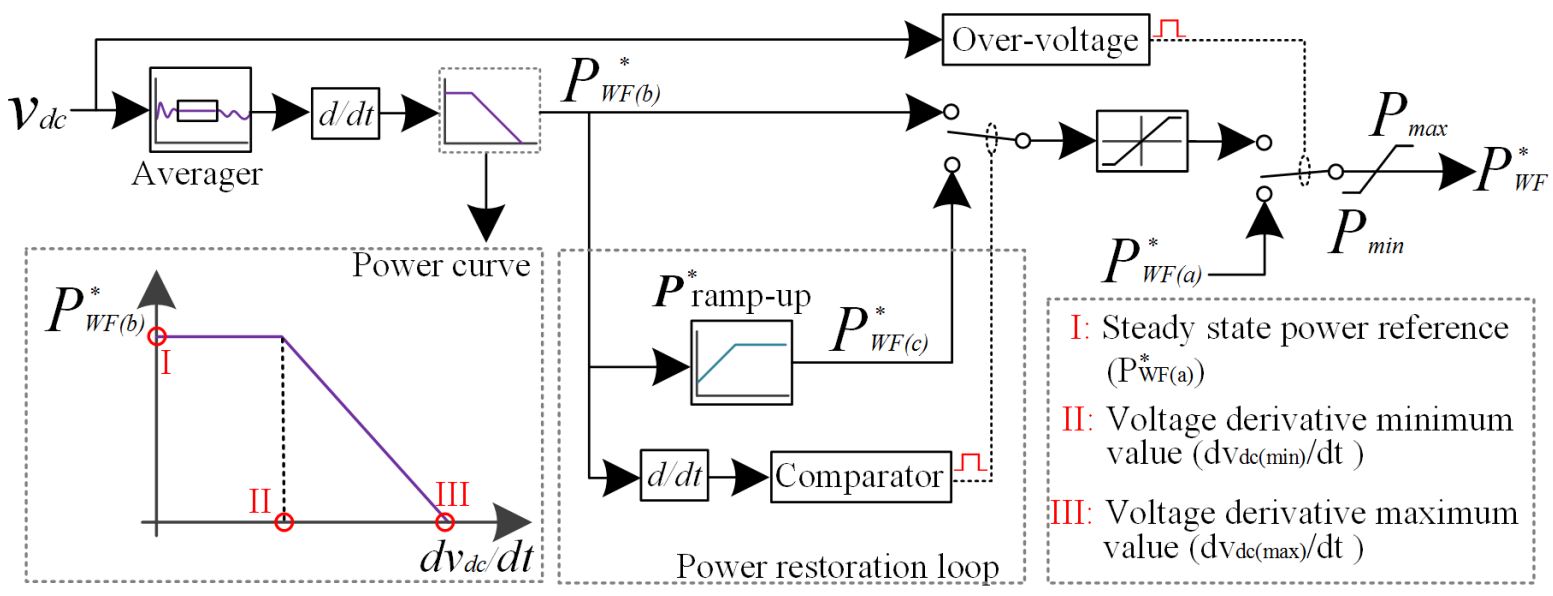

Figure 1: Master controller design.

$d v_{d c(\min )} / d t$ and $d v_{d c(\max )} / d t$ determine the operating range of $d v_{d c} / d t$ and consequently the slope of the power characteristic. Such values are supposed to be editable settings on the master controller and should be set according to the system dynamics. Prior to the $d v_{d c} / d t$ calculation, a $5 \mathrm{~ms}$ averaging time window has been integrated to reduce noise and avoid faulty adjustments of power reference. Moreover, a power restoration loop is also included within the master controller which ramps-up the power reference $\left(P_{W F(c)}^{*}\right)$ smoothly following a successful clearance of the fault and provides a non-oscillatory power restoration to the system. The ramp-up rate of the restoration loop has been set to 1 p.u./200 ms. During the controller operation in the restoration period, the MPPT is disabled, hence the $d v_{d c} / d t$ has no impact on the power reference. For voltage stability issues, the restoration loop is initiated with a $100 \mathrm{~ms}$ delay. The output of the master controller is theoretically expected to take values in the range of 1 (theoretical maximum of $P_{W F(a)}^{*}$ ) and 0 . However, due to the WTGs inertia and dynamics involved, the minimum level has been set to $30 \%$ of the rated value ( 0.3 p.u.). The controller is reset to enable tracking of the $P_{W F(a)}^{*}$ trajectory when the power is restored to $P_{W F(a)}^{*}$, and the DC voltage is below the $100 \mathrm{~ms}$ over-voltage threshold. The whole design of the proposed master controller is build by utilising a sampling frequency of $96 \mathrm{kHz}$ which corresponds to the preferred rate for DC instrument transformer applications according to IEC 61869-9 [23].

\section{Power system modelling and control}

\subsection{MT-HVDC grid}

Fig. 2 illustrates the case study network consisting of two FRC-PMSGs wind farms connected to a $400 \mathrm{kV}$ onshore AC grid via dedicated MMCs and DC lines. Wind Farms I and II are rated at 100 MVA (50 $\times 2$ MVA $)$ and 50 MVA $(25 \times 2$ MVA) respectively. The meshed three-terminal DC network is symmetric 
monopole and operates at $\pm 400 \mathrm{kV}$, while the DC cable models adopt the distributed parameter line representation, which is based on the Bergerons travelling wave method also being used in the electromagnetic transient program (EMTP) [24]. In comparison with the $\pi$ section line model, the distributed line represents the wave propagation phenomena and line end reflections with much better accuracy. The parameters used for the DC cable modelling and the MTDC grid are presented in Table 1.

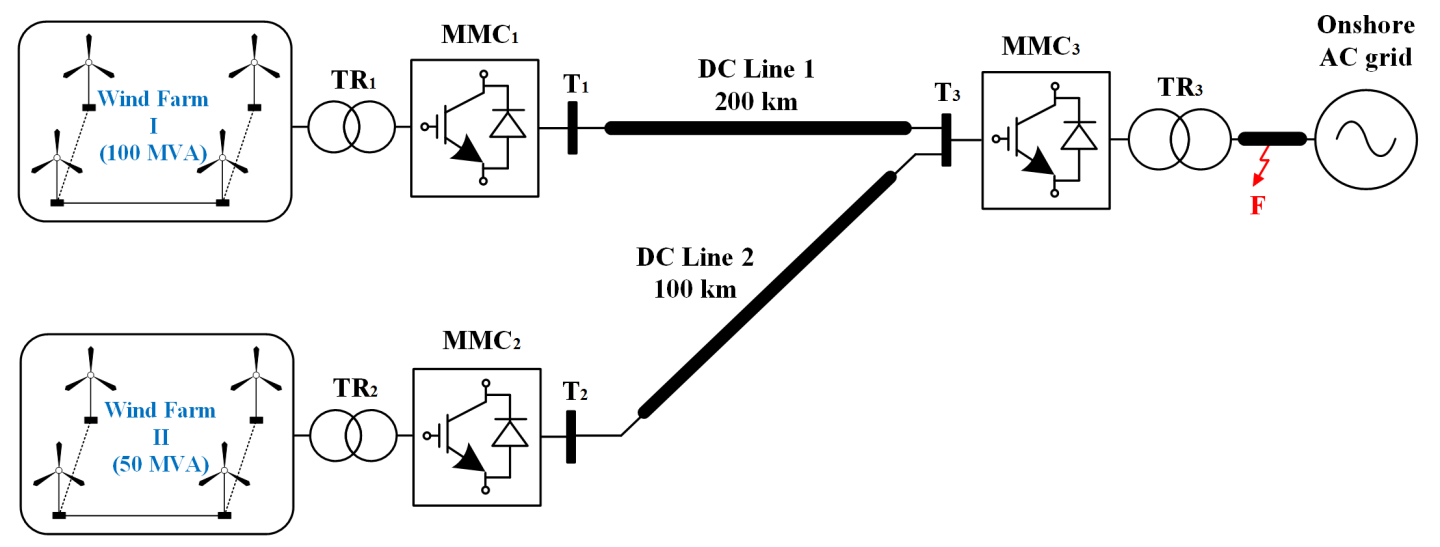

Figure 2: Wind farm integration using a three-terminal HVDC system.

Table 1: DC Cable and MTDC Grid Parameters

\begin{tabular}{ll}
\hline \hline Parameter & Value \\
\hline DC cable resistance $\left[R_{D C}\right]$ & $15.0 \mathrm{~m} \Omega / \mathrm{km}$ \\
DC cable inductance $\left[L_{D C}\right]$ & $0.96 \mathrm{mH} / \mathrm{km}$ \\
DC cable capacitance $\left[C_{D C}\right]$ & $0.012 \mu \mathrm{F} / \mathrm{km}$ \\
\hline AC onshore voltage $(\mathrm{L}-\mathrm{L}, \mathrm{RMS})$ & $400 \mathrm{kV}$ \\
AC frequency & $50 \mathrm{~Hz}$ \\
DC voltage & $\pm 400 \mathrm{kV}$ \\
$\mathrm{TR}_{1}, \mathrm{TR}_{2}$ ratings & $66 \mathrm{kV} / 400 \mathrm{kV}$ \\
$\mathrm{TR}_{3}$ rating & $400 \mathrm{kV} / 400 \mathrm{kV}$ \\
\hline \hline
\end{tabular}




\subsection{Wind turbines}

As shown in Fig. 3(a), the wind turbine considered is direct drive and includes three individual control sub-systems for the pitch mechanism, the machine-side converter (MSC), and the grid-side converter (GSC). The pitch controller is employed to regulate the pitching angle of the blades in order to adjust the rotor speed with respect to the wind speed, while the purpose of the MSC controller for the normal operation is to allow the maximum power point tracking (MPPT) through conventional rotor flux $\left(\lambda_{M}\right)$ oriented torque (current) control of the synchronous generator [25]. Such a vector control principle implies that the magnetising $d$-axis is aligned with the $\lambda_{M}$, produced by the permanent magnet, and the $q$-axis is shifted by $90^{0}$ ahead of the $d$-axis in the direction of rotor rotation. Under these control frame conditions, the $i_{d}$ current component would produce reactive power, and $i_{q}$ would be entirely responsible for the torque (power) production as formulated below.

The electro-magnetic (i.e. reference) torque of a $2 P$-pole generator can be expressed as follows [16]:

$$
T_{\text {set }}=\frac{3}{4} \cdot P \cdot \lambda_{M} \cdot i_{q s}^{*}
$$

Hence, for a particular torque reference setting $\left(T_{\text {set }}\right)$, the respective $q$-axis stator current, serving as a control variable $\left(i_{q s}^{*}\right)$, can be easily obtained using (1) as depicted in Fig. 3(a) and Fig. 3(b) at MSC controller.

\begin{tabular}{ll} 
Table 2: Wind Turbine Specifications and Ratings \\
\hline \hline Parameter & Value \\
\hline Generator nominal power & $2 \mathrm{MVA}$ \\
Generator nominal voltage & $690 \mathrm{~V}$ \\
Generator reactances Xd, Xq & $1.3,0.475$ p.u. \\
Converter DC-link voltage & $1200 \mathrm{~V}$ \\
DC-link capacitance & $90 \mathrm{mF}$ \\
GSC AC voltage & $575 \mathrm{~V}$ \\
TR $_{\mathrm{WT}}$ rating & $575 \mathrm{~V} / 66 \mathrm{kV}$ \\
\hline \hline
\end{tabular}

A structural block diagram of the generator (MSC) controller in Fig. 3(b) shows that the resistive voltage drop has been neglected in the state feedback loops, which is a valid assumption for MW range wind turbine generators to have very low resistances. As indicated in the same figure, the function of the GSC controller is two-fold [26]: (i) the DC-link voltage regulation by adjusting the active power delivered to the AC grid through variations of the $q$-axis line current ; and (ii) the AC-grid voltage control by manipulating the 


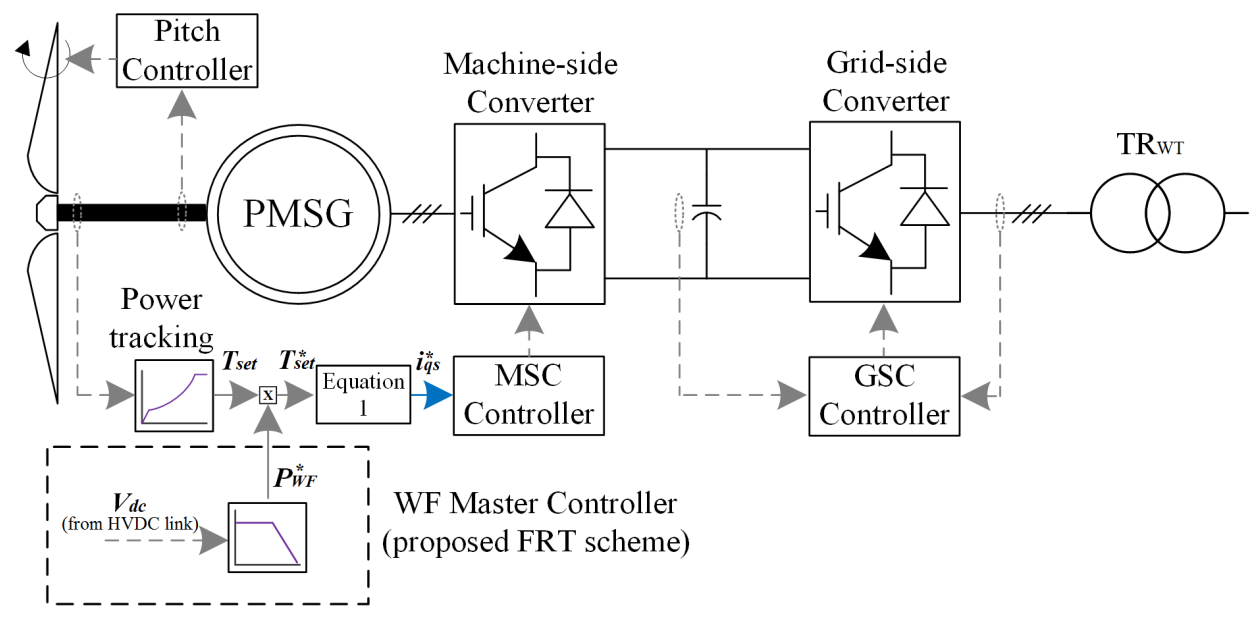

(a) Detailed schematic of PMSG and FRC

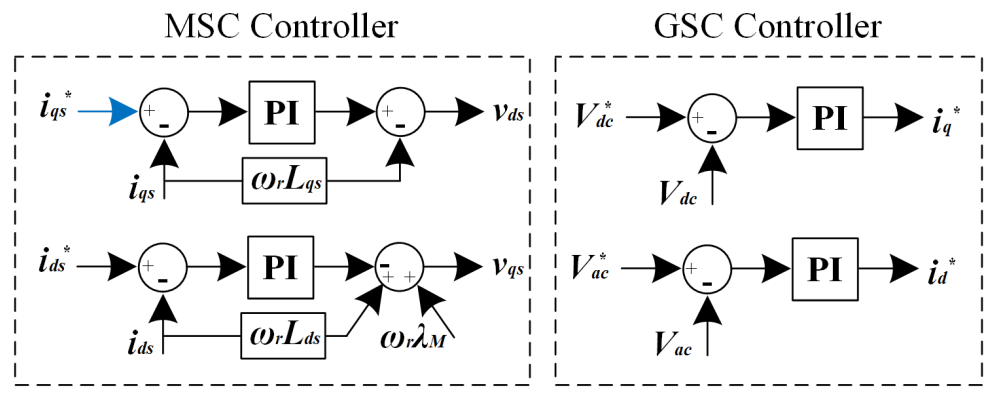

(b) Representation of the entire control structure of the FRC

Figure 3: General overview of the PMSG-FRC modelling and control configuration. 
reactive power via the $d$-axis line current. This is achieved in a similar manner as with the MSC vector control scenario.

\subsection{Modular multi-level converters (MMCs)}

The MMC model used for the studies presented in this paper, is a 301-level Type 3 and has been developed utilising the analyses in [27] and [28]. Specifically, the entire MMC is represented by the controlled voltage and current sources as illustrated schematically in Fig. 4 [8]. The respective control signals can be written as follows:

$$
\begin{aligned}
v_{c t r(j, k)} & =v_{C t o t(j, k)} \cdot s_{(j, k)} \\
i_{c t r(j, k)} & =i_{(j, k)} \cdot s_{(j, k)} \\
s_{(j, k)} & =\frac{1}{N} \sum_{i=1}^{N} s_{(j, k)(i)}
\end{aligned}
$$

where the index $j$ defines the phase $(j=a, b, c)$, the index $k$ signifies the arm position $(k=u$ for the upper arm and $k=l$ for the lower arm), $s_{(j, k)}$ is the sum of switching functions of the arm $(j, k)$ given by (4), $v_{C t o t(j, k)}$ is the sum of all capacitor values of an arm, $i_{(j, k)}$ is the current flowing through a particular arm, $N$ is the number of sub-modules, and $s_{(j, k)(i)}$ is the switching function of each sub-module.

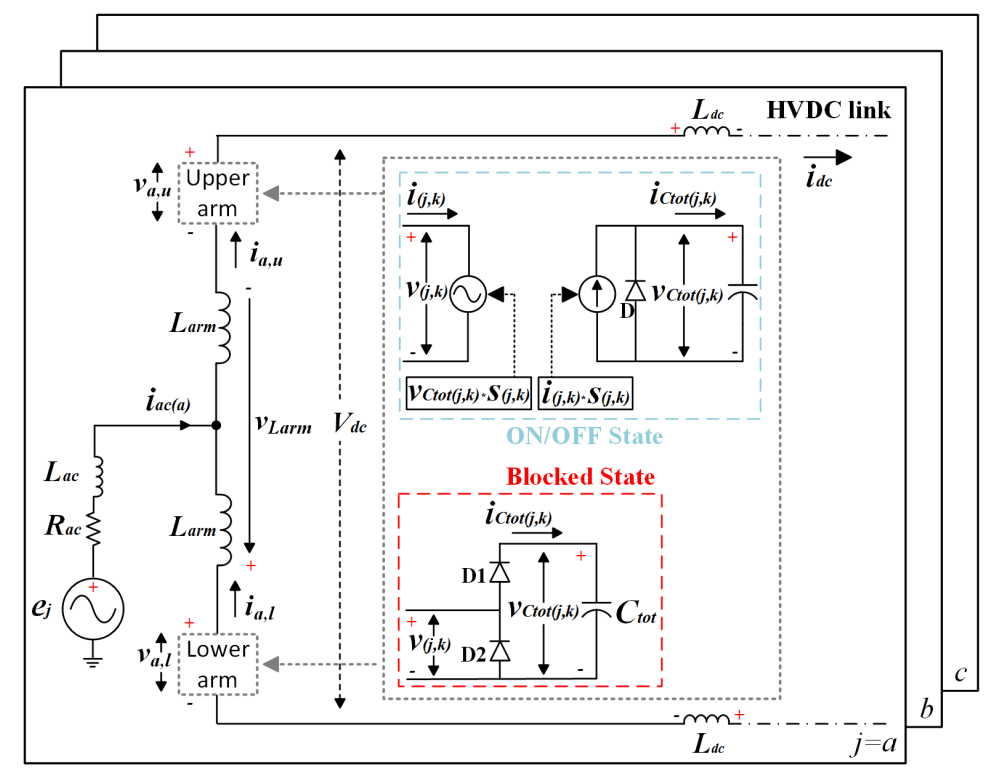

Figure 4: Detailed schematic with a three-phase equivalent of the MMC Type 3 model. 
The corresponding DC voltage expressions in generic form are:

$$
\begin{aligned}
& V_{d c}=v_{(j, u)}+v_{(j, l)} \\
& \frac{V_{d c}}{2}=v_{(j, u)}+L_{a r m} \frac{d i_{(j, u)}}{d t}-L_{a c} \frac{d i_{a c(j)}}{d t}-R_{a c} \cdot i_{a c(j)}+e_{(j)} \\
& \frac{V_{d c}}{2}=v_{(j, l)}+L_{a r m} \frac{d i_{(j, l)}}{d t}+L_{a c} \frac{d i_{a c(j)}}{d t}+R_{a c} \cdot i_{a c(j)}-e_{(j)}
\end{aligned}
$$

where $v_{(j, u)}$ and $v_{(j, l)}$ are the output voltages of upper and lower arms in phase $j, L_{a r m}$ and $L_{a c}$ are the arm and AC-side inductance respectively, $R_{a c}$ is the AC-side resistance, and $e_{(j)}$ is the AC-side grid phase voltage.

The upper and lower arm currents in a given phase $j$ can be expressed by:

$$
\begin{aligned}
& i_{(j, u)}=\frac{i_{a c(j)}}{2}+i_{\operatorname{diff}(j)} \\
& i_{(j, l)}=-\frac{i_{a c(j)}}{2}+i_{\operatorname{diff}(j)}
\end{aligned}
$$

where $i_{a c(j)}$ is the output/input AC phase current, and $i_{\text {diff }(j)}$ is the differential current which can be defined as:

$$
\begin{aligned}
i_{d i f f(j)} & =\frac{i_{(j, u)}+i_{(j, l)}}{2}=i_{d c(j)}+i_{c c(j)} \\
i_{d c} & =i_{d c(a)}+i_{d c(b)}+i_{d c(c)}
\end{aligned}
$$

where $i_{d c(j)}$ is the DC phase current and $i_{c c(j)}$ is the circulating current coming from the imbalance of the upper and lower arm voltages of phase $j$ [29]. Taking the neutral point of the DC link as a reference point, the latter can be expressed as follows:

$$
\begin{aligned}
v_{(j, u)} & =L_{a r m} \frac{d i_{(j, u)}}{d t}=v_{\operatorname{diff}(j)}-v_{a c(j)} \\
v_{(j, l)} & =L_{a r m} \frac{d i_{(j, l)}}{d t}=v_{d i f f(j)}-v_{a c(j)} \\
v_{d i f f(j)} & =\frac{V_{d c}}{2}-v_{(j, u)}=-\frac{V_{d c}}{2}+v_{(j, l)}=\frac{v_{(j, l)}-v_{(j, u)}}{2}
\end{aligned}
$$

where $v_{d i f f(j)}$ is the differential voltage between the upper and lower arm i.e. the inner e.m.f generated.

By combining (8), (9), (12) and (13), the following important control relationship can be derived:

$$
e_{(j)}=\left(\frac{L_{a r m}}{2}+L_{a c}\right) \frac{d i_{a c(j)}}{d t}+R_{a c} \cdot i_{a c(j)}+v_{d i f f(j)}
$$

The AC current is therefore controlled through the inner e.m.f $v_{\text {diff }(j)}$, thus, the classical current vector control strategy for conventional 3-phase converters is applicable. The control structures of an MMC appears in Fig. 5. 


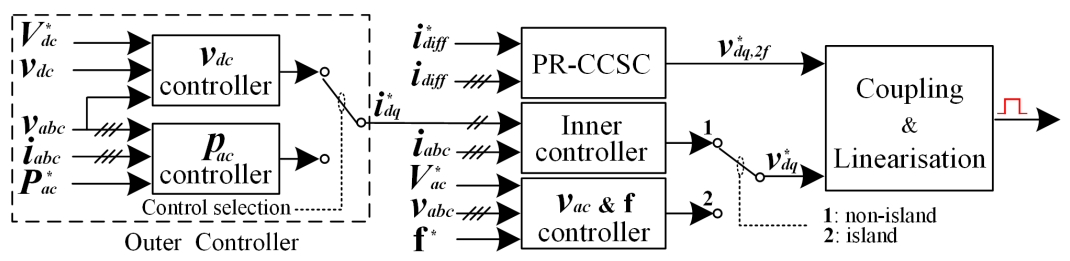

(a) Representation of the entire control structure of the MMC

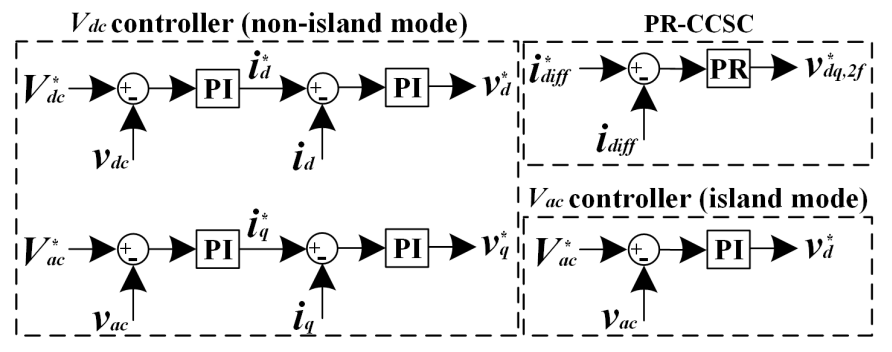

(b) Detailed representation of the sub-controllers

Figure 5: General overview of the MMC control configuration.

The key feature for the implementation of the DC system shown in Fig. 2 is the selection between the islanded and non-islanded control modes, which is determined by the type of the AC source connected. For the interconnection of the wind farms (connected via $\mathrm{MMC}_{1}$ and $\mathrm{MMC}_{2}$ ), the islanded mode has been chosen. Such a control scheme is adopted when the VSC converters are connected to an AC system with asynchronous generation (notably offshore wind) or a passive load. In this case, the voltage and frequency control $\left(V_{a c}^{*}\right)$ is selected and the inner current controller may be bypassed [22] as shown in as depicted in Fig. 5(a). Another benefit of this approach is that a phase-locked-loop (PLL) can be eliminated as the frequency and phase of the AC voltage are directly set by the controller itself [30]. The underlying control procedure is carried out using the d-axis voltages as depicted in Fig. 5(b) [31]. The regulated power transfer from the offshore WFs to the onshore $\mathrm{AC}$ network is done via $\mathrm{MMC}_{3}$ with $\mathrm{DC}$ voltage control, which ensures that the DC-link voltage remains within safe limits.

When the AC network, where an MMC is connected, operates under unbalanced conditions, the asymmetric circulating currents having negative and positive sequence components are generated inside the converter [32]. Such currents flow in each arm at double the fundamental frequency and introduce additional losses. In order to eliminate such currents, a proportional-resonant circulating current suppression controller (PR-CCSC) has been integrated into the control structure of the MMC as described in [33]. The controller is included in the operation of the converter in either the islanded or non-islanded mode. Its output is an additional control signal $v_{a b c, 2 f}$ which is input to the coupling and linearisation block, where the operations like capacitor voltage balancing and switching functions are implemented. The converter 
parameters for the MMC are summarised in Table 3.

Table 3: MMC Parameters

\begin{tabular}{ll}
\hline Parameter & Value \\
\hline DC voltage $\left[V_{D C}\right]$ & $\pm 400 \mathrm{kV}$ \\
Number of SMs per arm & 301 \\
IGBT $\left[R_{o n}\right]$ & $1 \mathrm{~m} \Omega$ \\
Equivalent arm capacitance $\left[C_{\text {arm }}\right]$ & $25 \mu \mathrm{F}$ \\
Arm inductance $\left[L_{\text {arm }}\right]$ & $0.1 \mathrm{p.u.}$ \\
\hline \hline
\end{tabular}

\section{Performance evaluation}

\subsection{Simulation studies: Three phase Fault}

The effectiveness of the proposed scheme is demonstrated for a three-phase short circuit fault at the onshore AC grid, as the most severe case for a power system. The fault is activated at $\mathrm{t}=0.2 \mathrm{~s}$ while lasting for $250 \mathrm{~ms}$.

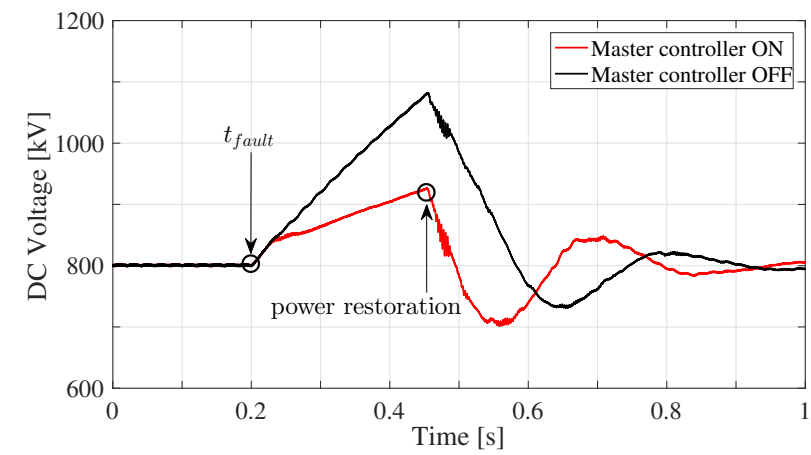

(a) DC-link voltage at $\mathrm{T}_{1}$

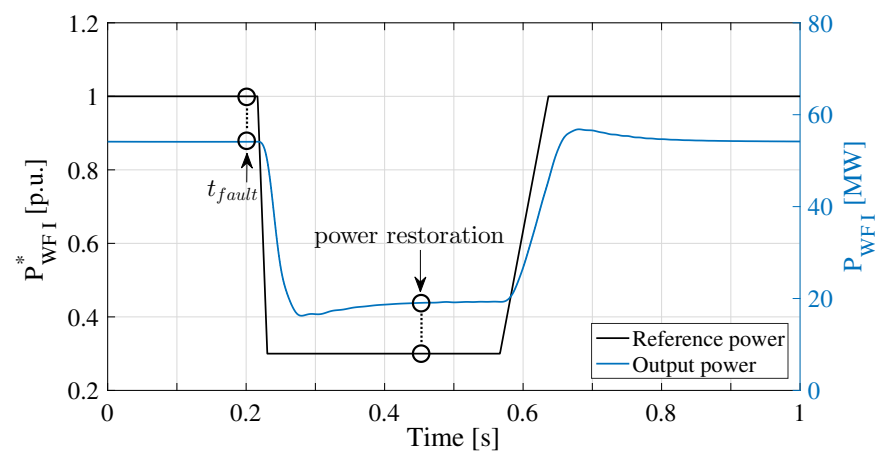

(c) Reference and output power for WF I

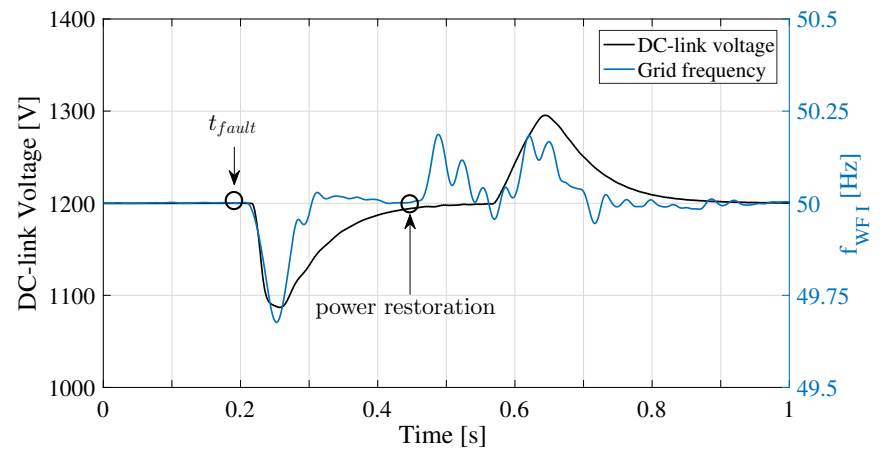

(b) FRC DC-link voltage and AC grid frequency at WF I

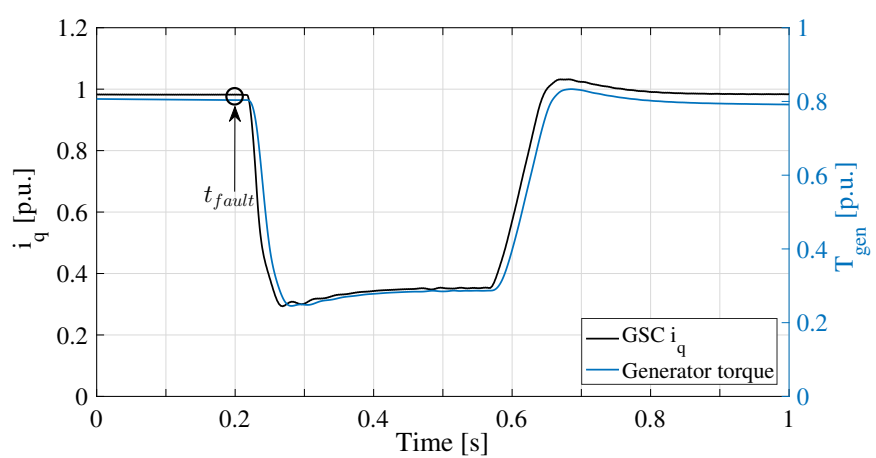

(d) Generator torque and $\mathrm{i}_{q}$ current of GSC

Figure 6: WF I response for a three-phase fault. 
Figs. 6(a) and 7(a) clearly show the DC voltage limitation when the master controller in each WF is enabled. Once the master controllers are activated, the DC voltage at both terminals reaches its peak at approximately 1.1 p.u. (i.e. $915 \mathrm{kV}$ ) compared to the situation when they are deactivated with the DC voltage attaining a value of around 1.3 p.u. (i.e. $1090 \mathrm{kV}$ ). Bearing in mind that the permissible limit of the DC link for voltage disturbances is considered to be 1.2 p.u., the proposed scheme clearly enhances the ability of the system to withstand this fault without using any additional hardware (i.e. neither communication links for transmitting signals nor a DC chopper).

Figs. 6(b), 6(c) and 6(d) as well as Figs. 7(b), 7(c) and 7(d) show the correlation between the power reference, the DC link voltage of the FRC, the offshore AC frequency and the current in the $q$-axis of an indicative PMSG (with the GSC being responsible for the DC link voltage control). This is accomplished by regulating the power delivered to the grid and for this reason the current in the $q$-axis is reduced proportionally to the decrease of the power reference to maintain the DC link voltage and as a result achieve the desirable curtailment of the overall active power output. This forces the output to be reduced from 1.0 p.u. to approximately 0.3 p.u.

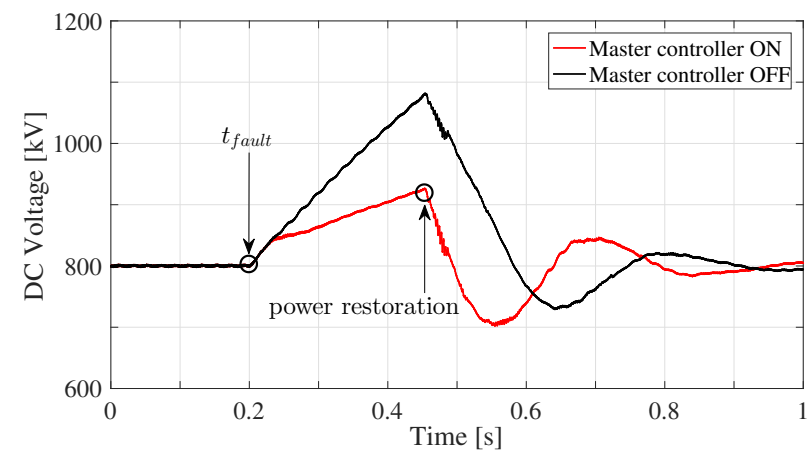

(a) DC-link voltage at $\mathrm{T}_{2}$

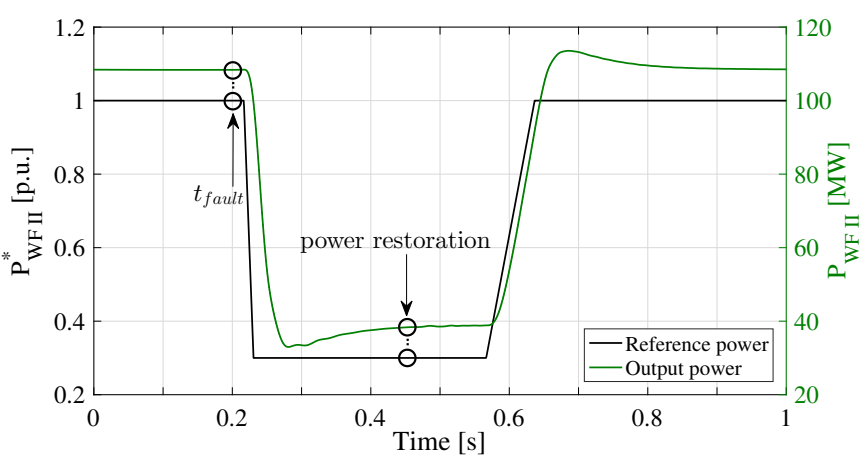

(c) Reference and output power for WF II

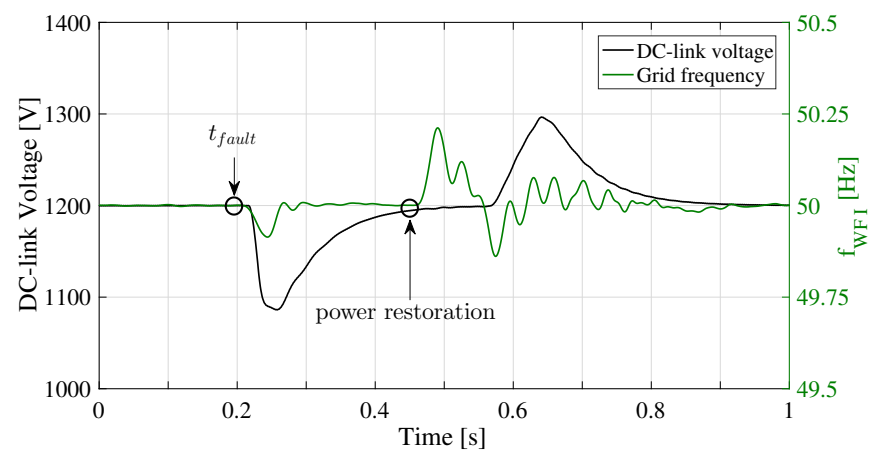

(b) FRC DC-link voltage and AC grid frequency at WF II

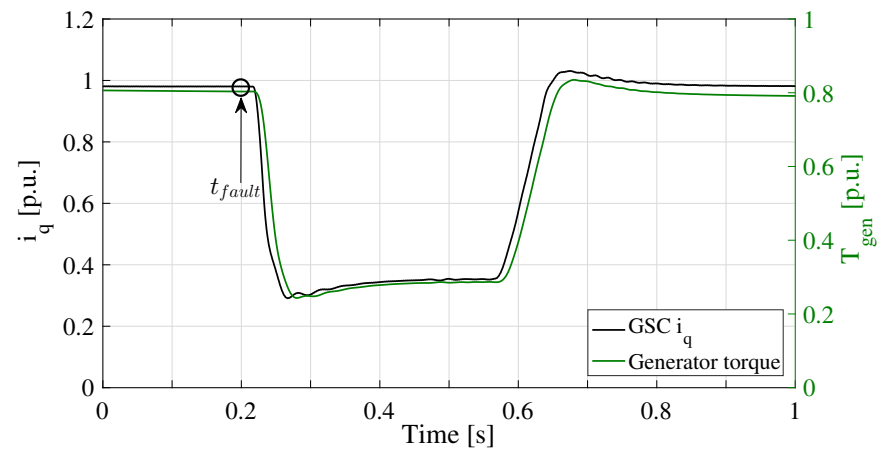

(d) Generator torque and $\mathrm{i}_{q}$ current of GSC

Figure 7: WF II response for a three-phase fault.

At $t=0.45 \mathrm{~s}$, the fault is cleared and the restoration process is initiated. As illustrated in Figs. 6(c) 
and 7(c), the power is smoothly restored to the pre-fault values since the power tracking curve is avoided during the restoration cycle. This approach offers a non-oscillatory restoration preserving the power system stability. It should be noted here that the input to the power restoration loop is $P_{W F(b)}^{*}$ (which only appears internally) is different from the actual power reference $P_{W F}^{*}$ which is depicted in the graphs. Consequently, the signal $d P_{W F(b)}^{*} / d t$ starts having positive values once the DC voltage starts falling back to normal. This is easily detected by the comparator and hence the power restoration loop is initiated (after $100 \mathrm{~ms}$ delay).

\subsection{Simulation studies: Single-Phase to Earth \& Two-Phase Faults}

The proposed scheme has been additionally tested under the influence of a single-phase to earth fault and a two-phase fault, which represent a more common case for power systems. Exactly as before, the fault inception is on $\mathrm{t}=0.2 \mathrm{~s}$ and has a duration of $250 \mathrm{~ms}$.

Figs. 8(a) and 8(b) illustrate DC voltage at terminals $\mathrm{T}_{1}$ and $\mathrm{T}_{2}$ respectively during a two-phase fault, when the controller is both activated and deactivated. The influence of the controller on the limitation of the DC voltage controller is obvious on the graphs. For clarity, it is noted that without the controller, the DC voltage increases up to approximately 1.16 p.u. (i.e. $930 \mathrm{kV}$ ), whereas with the controller enabled the DC voltage remains below 1.04 p.u. (i.e. $830 \mathrm{kV}$ ). Even though in this case the application of the controller is not considered essential for the protection of the equipment's integrity (i.e. DC voltage remains below the permissible limit even during the fault), it still forces the voltage to remain as low as possible and therefore protects the equipment from unnecessary electrical stresses, hence ensures that its lifetime is not compromised.

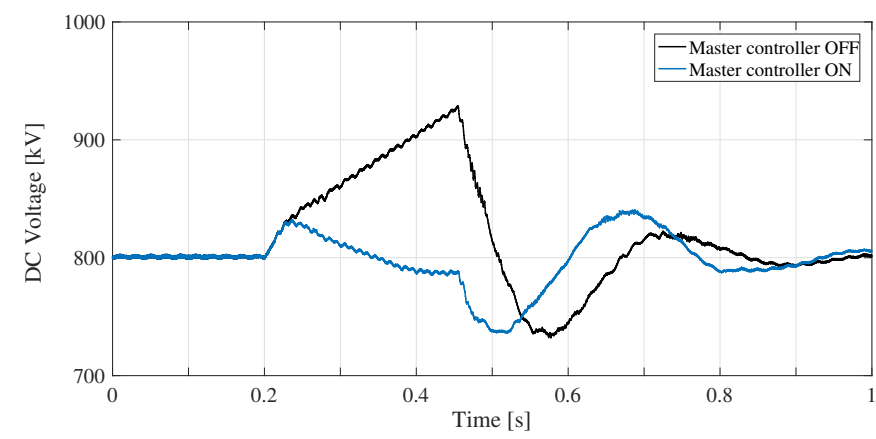

(a) DC-link voltage at $\mathrm{T}_{1}$

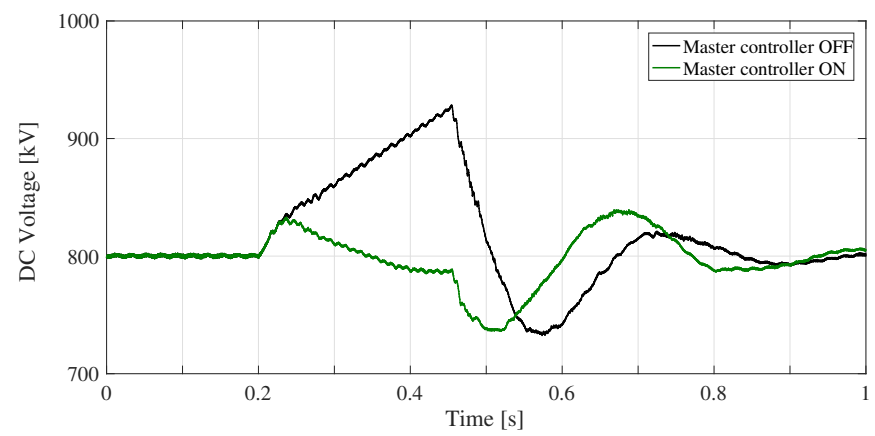

(b) DC-link voltage at $\mathrm{T}_{2}$

Figure 8: DC Voltage response for two-phase fault.

As far as the single-phase to earth fault is concerned, we firstly point out that because its impact upon the DC voltage increase was insignificant (i.e. below 1.02 p.u., which is the predefined over-voltage element 


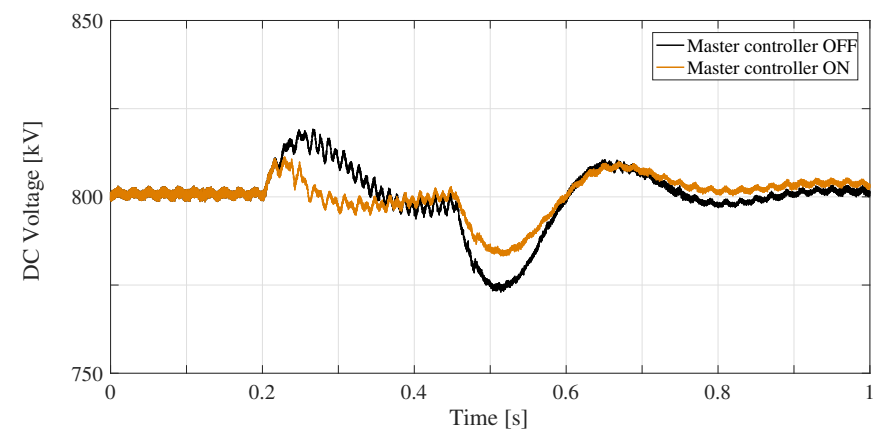

(a) DC-link voltage at $\mathrm{T}_{1}$

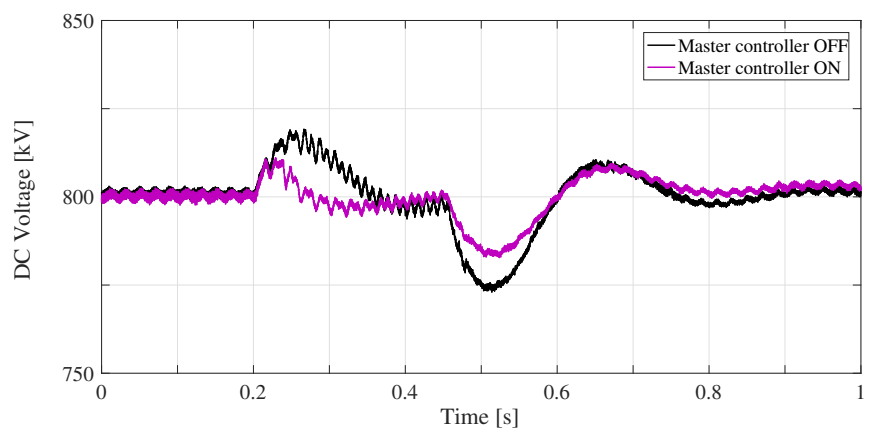

(b) DC-link voltage at $\mathrm{T}_{2}$

Figure 9: DC Voltage response for single-phase to earth fault.

threshold for triggering the controller's operation), the master controller could not be activated. Since the controller offers the advantage of being easily tunable, we reset the threshold to be on 1.005 p.u. for this specific case study. With the modified threshold, the master controller is now activated even for a low impact fault such as the single-phase to earth fault. Figs. 9(a) and 9(b) capture the DC voltage at terminals $\mathrm{T}_{1}$ and $\mathrm{T}_{2}$ demonstrating the beneficial operation of the controller even in such a case. Specifically, the controller achieves a DC voltage reduction of approximately $20 \mathrm{kV}$ in both terminals.

\subsection{Simulation studies: Influence of the Master Controller Settings}

In this section, we present the results of a sensitivity analysis evaluating the performance of the master controller under various slopes of the power characteristic curve (es explained in Fig. 1). This simulation has only been performed for a three-phase fault, which represents the most severe case according to the results shown in Sections 4.1 and 4.2.

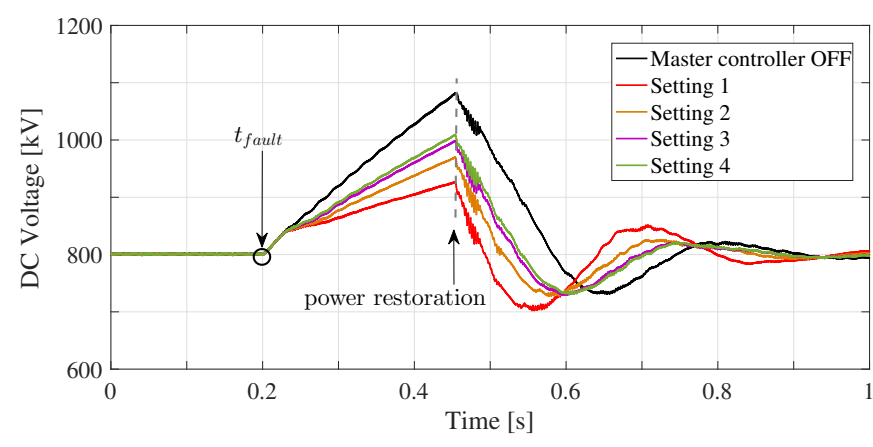

(a) DC-link voltages at $\mathrm{T}_{1}$

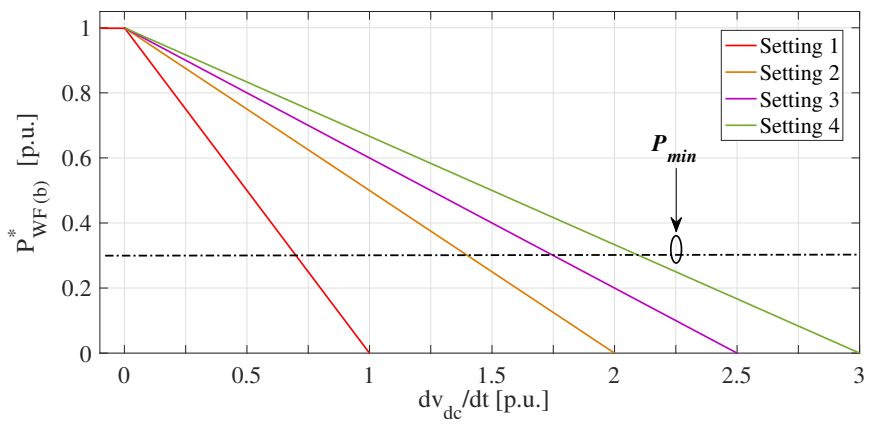

(b) Power curve settings

Figure 10: DC Voltage response for three-phase fault and different settings on the master controller.

Fig. 10(b) illustrates the various settings (i.e. slopes of power curve) used to perform the analysis. Accordingly, Fig. 10(a) shows the results of the DC voltage at terminal $\mathrm{T}_{1}$ for each case. As it can be observed, 
Setting 1 (i.e. $d v_{d c} / d t$ is set to 1 p.u.) offers to the system the largest DC voltage reduction, therefore it is the selected setting for the master controller. Regarding the rest of the settings, the decrease of DC voltage achieved is much less and especially Settings 3 and 4 cannot manage to keep the DC voltage within the safety limit (i.e. 1.2 p.u., which corresponds to $960 \mathrm{kV}$ ). Additionally, in all cases we observe that after power restoration the DC voltage returns to its nominal value a slightly oscillated manner within $300 \mathrm{~ms}$, which however does not threaten the system's stability. As explained in Section 2.2, the slope characteristic can be changed according to the system dynamics and the required performance/speed of operation. In the simulations presented in this article, the $d v_{d c(\min )} / d t$ was set to zero to enable fast operation of the controller (taking into account that over-voltage threshold and the averager would prevent unnecessary adjustments of power). If the $d v_{d c(\min )} / d t$ setting was set to a non-zero value, the controller would simply start adjusting the active power reference with a small time delay (i.e. the time required for the $d v_{d c} / d t$ to reach the non-zero value).

\subsection{Experimental results}

A hardware prototype for the validation of the proposed controller was designed and implemented in OP5600 Opal-RT Real-Time Digital Simulator [34] (Fig. 11), which is equipped with an OP5330 analogueout card [35] (16 single-ended digital output channels with a 16-bit resolution digital-to-analogue converter) and an OP5340 analogue-in card (with an input signal ranging from $\pm 20 \mathrm{~V}$ to $\pm 120 \mathrm{~V}$ ) [36]. The electrical connections are established using DB-37 slim breakout boards [37].

Fig. 11c shows the real-time model consisting of two subsystems, whereby subsystem I represents a 'virtual' HVDC link, in wihch the DC voltage $V_{d c}$ is measured and forms an input to subsystem II (through $\mathrm{A}_{\text {out }}$ and $\mathrm{A}_{\text {in }}$ boards). The master controller is simulated in subsystem II. During normal operation, subsystem I feeds subsystem II at $10 \mathrm{~V}$ representing the nominal voltage (i.e. 1.0 p.u.). The master controller is validated in real-time by applying a step change in DC voltage to subsystem I from 1.0 p.u. to 1.2 p.u. (i.e. from $10 \mathrm{~V}$ to $12 \mathrm{~V}$ ) as presented in Fig. 12a. The master controllers response to the aforementioned voltage change is illustrated in Fig. 12b; the power reference drops rapidly to 0.3 p.u. until the return of both the voltage to its nominal value and the power reference to its initial value (i.e. 1 p.u.).

The corresponding response of the experimental setup is additionally shown in Fig. 12c and d, where the input DC voltage and output power reference waveforms are captured on an oscilloscope. Due to the voltage step change, the power reference suddenly decreases from 1 p.u. to 0.3 p.u. It can be observed that the developed hardware prototype accurately follows the simulated response of the master controller. The same also applies to the restoration process, as it appears that the output power reference returns smoothly 


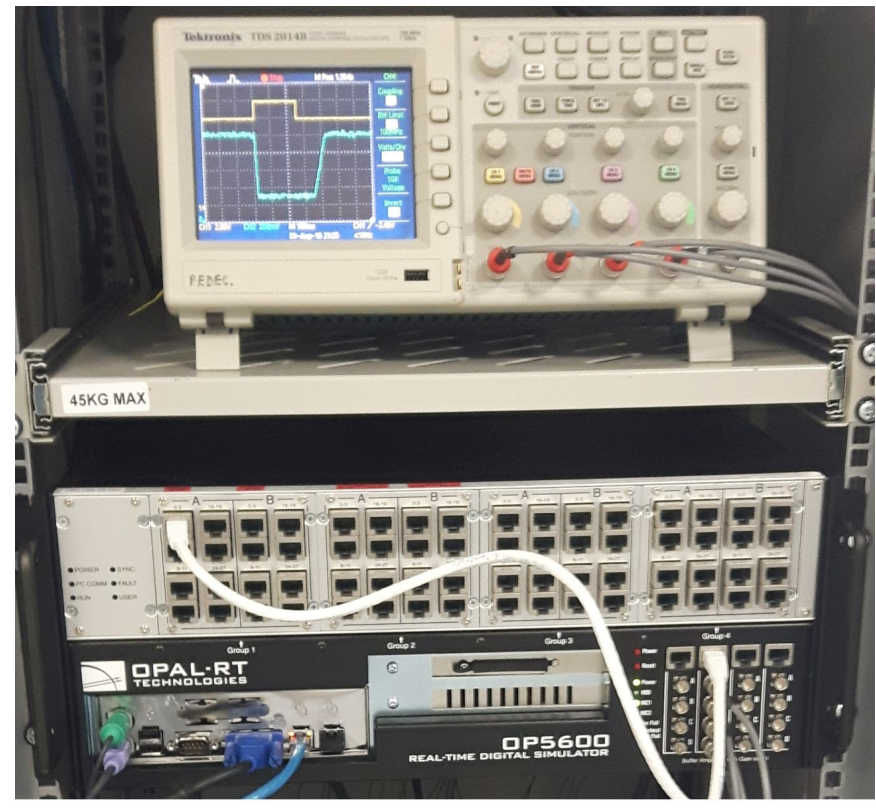

(a) OP5600 front view

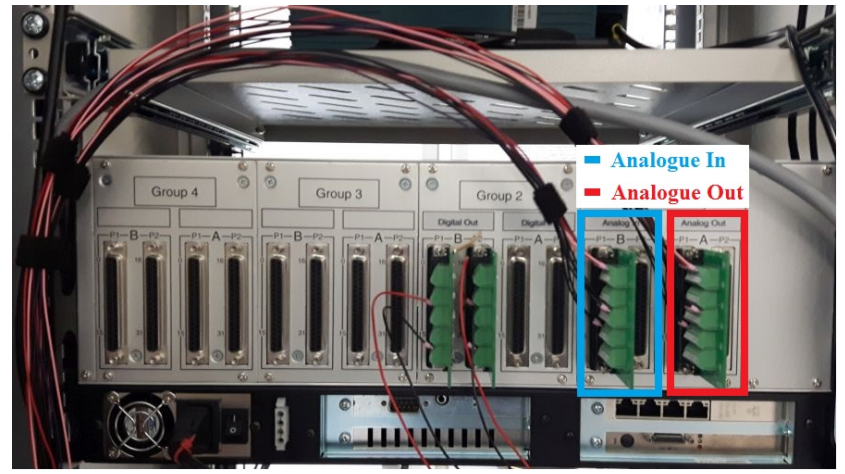

(b) OP5600 rear view

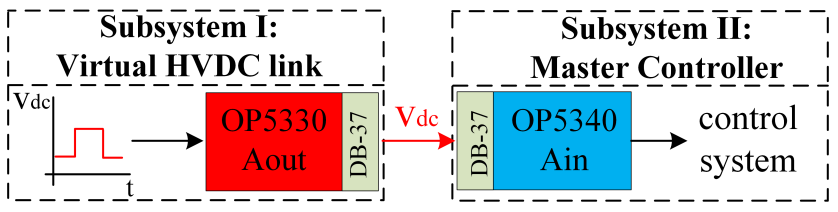

(c) Real-time model structure

Figure 11: Experimental Setup.

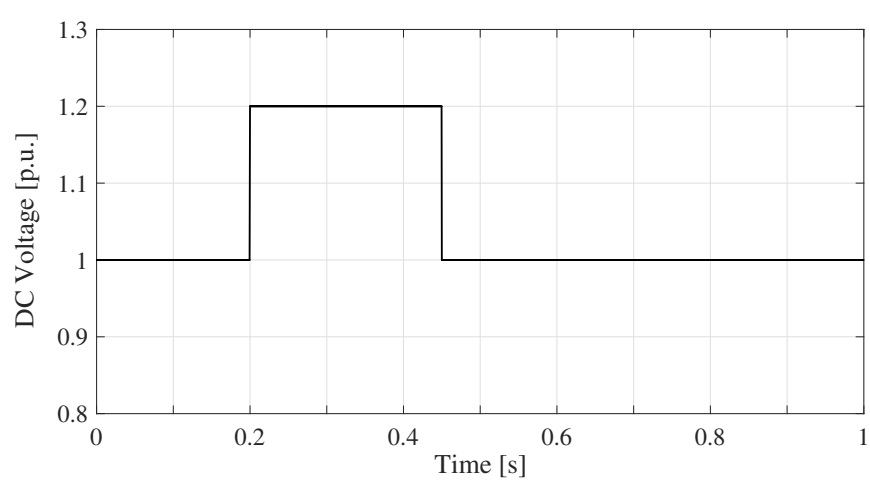

(a) Simulation: input DC voltage

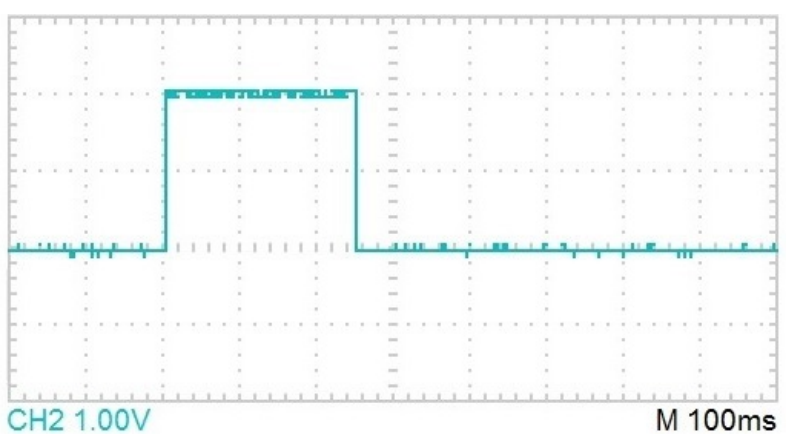

(c) Experiment: input DC voltage

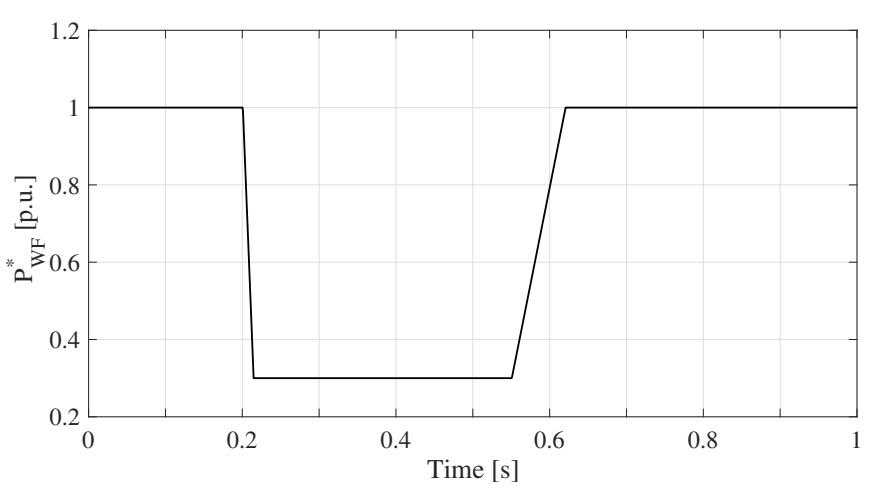

(b) Simulation: output power reference

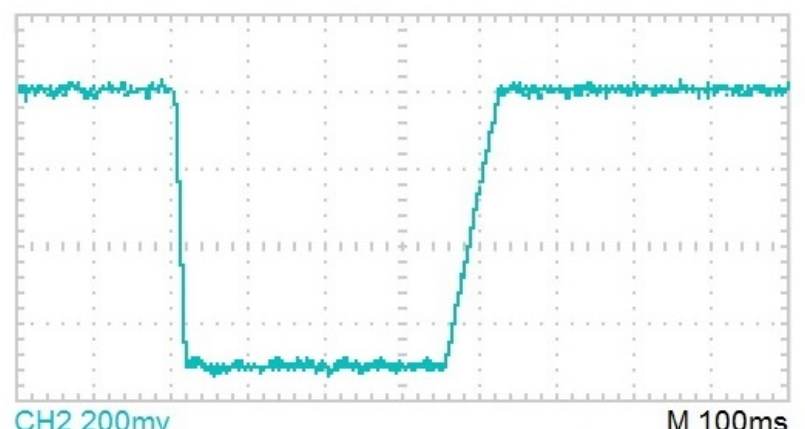

(d) Experiment: output power reference

Figure 12: Master controller response for a step change at input DC voltage.

and in an non-oscillatory fashion to its pre-fault value. 


\section{Conclusions}

Simulations of an example MT-HVDC system, comprising of two offshore WFs connected to the AC onshore grid via MMC-HVDC converters, have indicated that faults in close proximity to the onshore HVDC converter and especially major three-phase faults can result in significant transient over-voltages in the DC-links. The proposed FRT strategy has been proven able to provide fast dynamic response allowing to maintain the DC voltage within safety limits and ensuring integrity of the cables and other associated equipment under the challenging fault conditions imposed to the system. In terms of the post-fault restoration process, the results have also demonstrated the active power recovery to the pre-fault values in a non-oscillatory manner within $300 \mathrm{~ms}$. It should be pointed out that the developed FRT strategy benefits from the absence of any additional equipment or communication links offering further cost advantages and improved efficiency over most of the existing schemes. Furthermore, the controller is relatively simple requiring only small computational power for implementation and offers the great advantage of being easily tunable for use in different WF systems.

The simulation studies of the master controller operation have been verified in real-time on a hardware prototyping platform proving that the proposed strategy is practically feasible and of great potential to be successfully applied to actual large-scale systems.

\section{References}

[1] European Commission, Directive on the promotion of the use of energy from renewable energy sources 2009/28/EC, Official Journal of the European Union 52 (2009) 16-62.

[2] A. Ho, A. Mbistrova, G. Corbetta, The european offshore wind industry-key trends and statistics 2015, Tech. rep., EWEA (February 2016).

[3] J. Ladenburg, A. Dubgaard, Willingness to pay for reduced visual disamenities from offshore wind farms in denmark, Energy Policy 35 (8) (2007) 4059 - 4071.

[4] R. Swart, J. Horalek, M. Harfoot, G. Giebel, Europe's onshore and offshore wind energy potential: An assessment of environmental and economic constraints, Tech. Rep. 6/2009, EWEA (June 2009).

[5] J. Coelingh, A. van Wijk, A. Holtslag, Analysis of wind speed observations over the north sea, Journal of Wind Engineering and Industrial Aerodynamics 61 (1) (1996) 51 - 69. 
[6] K. Meah, S. Ula, Comparative evaluation of HVDC and HVAC transmission systems, in: Power Engineering Society General Meeting, 2007. IEEE, 2007, pp. 1-5.

[7] P. Bresesti, W. L. Kling, R. L. Hendriks, R. Vailati, HVDC connection of offshore wind farms to the transmission system, IEEE Transactions on Energy Conversion 22 (1) (2007) 37-43.

[8] D. Tzelepis, S. Ademi, D. Vozikis, A. Dysko, S. Subramanian, H. Ha, Impact of VSC converter topology on fault characteristics in HVDC transmission systems, in: IET 8th International Conference on Power Electronics Machines and Drives, 2016.

[9] European Commission, Establishing a network code on requirements for grid connection of generators, Official Journal of the European Union 59 (2016) 1-68.

[10] I. M. de Alegra, J. Andreu, J. L. Martn, P. Ibaez, J. L. Villate, H. Camblong, Connection requirements for wind farms: A survey on technical requierements and regulation, Renewable and Sustainable Energy Reviews 11 (8) (2007) 1858-1872.

[11] M. Tsili, S. Papathanassiou, A review of grid code technical requirements for wind farms, IET Renewable Power Generation 3 (3) (2009) 308-332.

[12] A. O. Rousis, O. Anaya-Lara, DC voltage control for fault management in HVDC system, Energy Procedia 80 (2015) $237-244$.

[13] D. Tzelepis, A. O. Rousis, A. Dysko, C. Booth, Enhanced DC voltage control strategy for fault management of a VSC-HVDC connected offshore wind farm, in: IET 5th International Conference on Renewable Power Generation, 2016.

[14] C. Feltes, H. Wrede, F. W. Koch, I. Erlich, Enhanced fault ride-through method for wind farms connected to the grid through VSC-based HVDC transmission, IEEE Transactions on Power Systems 24 (3) (2009) 1537-1546.

[15] B. Silva, C. L. Moreira, H. Leite, J. A. P. Lopes, Control strategies for AC fault ride through in multiterminal HVDC grids, IEEE Transactions on Power Delivery 29 (1) (2014) 395-405.

[16] G. Ramtharan, A. Arulampalam, J. B. Ekanayake, F. M. Hughes, N. Jenkins, Fault ride through of fully rated converter wind turbines with $\mathrm{AC}$ and DC transmission, IET Renewable Power Generation 3 (4) (2009) 426-438. 
[17] G. P. Adam, K. H. Ahmed, S. J. Finney, B. W. Williams, AC fault ride-through capability of a VSCHVDC transmission systems, in: IEEE Energy Conversion Congress and Exposition, 2010, pp. 3739_ 3745 .

[18] M. Mohammadi, M. Avendano-Mora, M. Barnes, J. Y. Chan, A study on fault ride-through of VSCconnected offshore wind farms, in: IEEE Power and Energy Society General Meeting, 2013, pp. 1-5.

[19] S. Nanou, S. Papathanassiou, Evaluation of a communication-based fault ride-through scheme for offshore wind farms connected through high-voltage DC links based on voltage source converter, IET Renewable Power Generation 9 (8) (2015) 882-891.

[20] G. Patsakis, S. Nanou, S. Papathanassiou, Fault ride through of VSC-HVDC connected offshore wind farms: A simplified model, in: EWEA 2015 Annual Event, 2015.

[21] M. Ndreko, M. Popov, M. A. van der Meijden, Study on FRT compliance of VSC-HVDC connected offshore wind plants during AC faults including requirements for the negative sequence current control, International Journal of Electrical Power \& Energy Systems 85 (2017) 97-116.

[22] A. Beddard, M. Barnes, Modelling of MMC-HVDC systems: An overview, Energy Procedia 80 (2015) $201-212$.

[23] IEC 61869-9: Instrument transformers - part 9: Digital interface for instrument transformers, BSI.

[24] H. Dommel, Digital computer solution of electromagnetic transients in single-and multiphase networks, IEEE Transactions on Power Apparatus and Systems PAS-88 (4) (1969) 388-399.

[25] S. Muyeen, A. Al-Durra, J. Tamura, Variable speed wind turbine generator system with current controlled voltage source inverter, Energy Conversion and Management 52 (7) (2011) 2688 - 2694.

[26] A. Dahbi, M. Hachemi, N. Nait-Said, M.-S. Nait-Said, Realization and control of a wind turbine connected to the grid by using PMSG, Energy Conversion and Management 84 (2014) 346 - 353.

[27] H. Saad, S. Dennetiere, J. Mahseredjian, P. Delarue, X. Guillaud, J. Peralta, S. Nguefeu, Modular multilevel converter models for electromagnetic transients, IEEE Transactions on Power Delivery 29 (3) (2014) 1481-1489.

[28] T. Vrana., Guide for the development of models for HVDC converters in a HVDC grid, Tech. rep., Cigre WG:B4.57 (2014). 
[29] K. Ilves, A. Antonopoulos, S. Norrga, H. P. Nee, Steady-state analysis of interaction between harmonic components of arm and line quantities of modular multilevel converters, IEEE Transactions on Power Electronics 27 (1) (2012) 57-68.

[30] L. Xu, B. W. Williams, L. Yao, Multi-terminal DC transmission systems for connecting large offshore wind farms, in: IEEE Power and Energy Society General Meeting - Conversion and Delivery of Electrical Energy in the 21st Century, 2008, pp. 1-7.

[31] U. N. Gnanarathna, S. K. Chaudhary, A. M. Gole, R. Teodorescu, Modular multi-level converter based HVDC system for grid connection of offshore wind power plant, in: IET 9th International Conference on AC and DC Power Transmission, 2010, pp. 1-5.

[32] J. W. Moon, C. S. Kim, J. W. Park, D. W. Kang, J. M. Kim, Circulating current control in MMC under the unbalanced voltage, IEEE Transactions on Power Delivery 28 (3) (2013) 1952-1959.

[33] S. Li, X. Wang, Z. Yao, T. Li, Z. Peng, Circulating current suppressing strategy for MMC-HVDC based on nonideal proportional resonant controllers under unbalanced grid conditions, IEEE Transactions on Power Electronics 30 (1) (2015) 387-397.

[34] OPAL-RT Technologies, OP5600 Real Time Digital Simulator, http://www.opal-rt.com/sites/default/ files/OP5600\%20Datasheet_2014(1).pdf, Assesed: 24-11-2016.

[35] OPAL-RT Technologies, OP5330 User Guide, http://www.opal-rt.com/sites/default/files/doc/ OP5330_User_Manual.pdf, Assesed: 24-11-2016.

[36] OPAL-RT Technologies, OP5340 User Guide, http://www.opal-rt.com/sites/default/files/doc/ OP5340_User_Manual.pdf, Assesed: 24-11-2016.

[37] Winford Engineering, BRKSD37F Rev A Datasheet, https://www.winford.com/download/brksd37f_ rev_a_datasheet.pdf, Assesed: 24-11-2016. 